\title{
Quality Assessment of Curriculum for Bu-Ali Sina Higher Education Department of Literature and Human Sciences
}

\author{
Ehsan Parvin ${ }^{* 1}$ \\ Esmaeil Aslani2 \\ Mehdi Babakhani² \\ Mohammadrasoul Parvin ${ }^{3}$

\begin{abstract}
"Department of Educational Planning, Faculty of Psychology \& Education, Allameh Tabataba"i University, Tehran, Iran ${ }^{2}$ Department of Instructional Technology, Faculty of Psychology \& Education, Allameh Tabataba'i University, Tehran, Iran ${ }^{3}$ Department of Executive Management, Sciences and research branch, Islamic Azad University, Ilam, Iran *Corresponding Author: Ehsan, Parvin, Email: Ehsan.parvin@hotmail.com
\end{abstract}

\section{Doi:10.5901/mjss.2015.v6n5p507}

\section{Abstract}

The current study aims at assessing the quality of higher education curriculum of Bu-Ali Sina University stressing on: curriculum objectives, curriculum contents, teaching and learning strategies and curriculum assessment strategies. The study population consists of higher education students and professors of human science department: 149 students and 20 professors in 2013-2014. Using Morgan table, sample volume is 103 students and 16 faculty members and simple random sampling was used at two levels of M.A. and PHD. Descriptive survey is the method. Research tool is a self-made questionnaire including 68 items whose validity and reliability were calculated using formal and content validity and Cronbach's alpha coefficient of 0.94 respectively. Analyzing the data gathered from the questionnaire, single-sample and independent $t$-test was used. The results show that curriculum objective, curriculum content, learning and teaching strategies and curriculum assessment strategies live up to the students' needs. Also, the perspective of the students and professors towards curriculum objectives, implementation strategies, curriculum content and curriculum assessment strategy is different.

Keywords: Quality Assessment, Curriculum, Higher Education

\section{Introduction}

Human is the most wonderful creature and the highest sign of God's power. Human tends to reach to all the attributes and perfection of God and reach to "caliph of Allah" and this is not possible but for true education (Gourchiyan \& Tansaz, 1995). Nowadays, humans are constantly facing various problems and events and need to be equipped with a set of skills and abilities supplying their scientific, individual, social and occupational needs so they can deal with the changes. One of the most important organizations in charge of creating such abilities is higher education which must meet these needs through curriculum of different majors. Higher education must enable the students to react to fast-growing social, economic and technological breakthroughs (Wheelahan \& Carter, 2001).

In the realm of curriculum, heart of educational system, there are a variety of approaches, each stressing on different aspects of human. Looking at the curriculum history and analyzing approaches of educational systems reveal the prevalence of one or some approaches in education. In our country's educational system and also many educational systems in the world, curriculum and teaching largely address cognitive domain of learners. This approach has trapped the learners within scientific issues. As a result, it has taken them towards one-dimensionality, dogmatism, unjustified belief, unreasonable pride and unfair dealing (Shabani, 2006). However, followers of "quality" believe that the overall objective of any curriculum is to ensure that the users would receive exactly what they need not less. Therefore, higher education institutions should seek ways to improve efficiency and quality of implementation of courses and curriculum. Unfortunately, curriculum is regarded as the missing link in higher education or at least little attention is given to its quality as it does not seriously and extensively step into higher education issues, policy and its implementation and there is not enough effort to analyze, evaluate, modify and change them. Moreover, regarding Iran's twenty-year perspective plan, the available capacities within higher education are not exploited in line with the country's scientific development goals. 
Taking a logical approach and specific depth to analyze the issue, one can realize that even the little actions taken are appreciable but considered as a darning and repair. Thus, it cannot take a significant role in the dynamics of higher education and subsequently its reaction (Ghassabi Chourasi et. al., 2013a).

The findings show that the success of human societies at all level s of education and parallel to it, higher quality, more effective management and compliance with teaching their needs have drawn specific attention to the point that leading observers to the global economy have identified education and educated work force as the basic factor for development not raw material, energy sources and capital (Javedani, 1998). The role of higher education in economic development, whether in economics based on advanced technologies or in the newly industrialized countries, is unique and outstanding. Socially speaking, higher education is again highly significant in the community development. In this regard, universities are the most important social centers which cause increase of contribution, social mobilization, and collective rationality, formation of national integration and development of civil institutions. Therefore, in general, higher education can be regarded as the most important factor driving national development (Iranmanesh \& Kamrani, 2004).

Quality refers to set of features and attributes of a product or service representing its ability in meeting the mentioned needs (Hawasbeigi, 2009) and each individual may approach quality differently given his/her own intended values. According to a definition, quality of an element is "its suitability for the intended purpose." Faculty members, students and employers approach quality differently. For instance, for employers, higher education quality means graduates would bear necessary knowledge, attitude and ability in carrying out duties assigned. However, for students, higher education quality equals their academic achievement (Ghassabi Chourasi et. al., 2013b) whereas higher education quality for faculty members refers to the rate of knowledge transfer and doing research. According to many experts, higher education has entered a new era for which "competition" and "quality" are the main features. Flannigan, one of the founders of quality management theories, maintains that "educational quality" is the key for "covert competition" among countries as the quality of products and services in each country is formed by the way of thinking, action, managers' decision-taking, teachers, economists, engineers and other educated groups of the society (Saleholiya, 1998). Constant promotion of science quality, higher education of university requires endogenous development of evaluation culture which in turn needs spirits and behaviors of self-assessment, self-adjustment and internal commitment to quality among followers and beneficiaries of higher education. The state of our scientific moral duty cannot be explained by will-oriented or error-oriented approaches. Rather, first, environmental background and structural logic must be understood. Secondly, interactive settings must be formed to include universities, scientific societies and professional bodies because extending professional moral happens through followers, beneficiaries of scientific and academic community and with the endogenous incidence and spread, not with advice and external culture (especially of the state type) (Farasatkhah, 2006). Thus, quality in higher education is not a stable point, rather it is a more strategic goal and Islamic duty with which the universities and educational institutions face (Abolgasem et. al., 2011) and it requires taking basic steps.

Knowing these issues, unfortunately state's higher education system has not managed to play its key and fundamental role in developing the country as expected for various reasons, especially ineffective implementation policies and not using available opportunities and potentials. At the moment, the state's higher education is facing challenges in creating equal educational system, improving curriculum quantity, consistency with community needs, productivity of offering institutions and the way public and private sectors contribute. In general, our higher education is a heterogeneous and disordered mass along with its poor quality and quantity. Scientific policy makers have not still managed to define an effective role for this collection and this is why (lack of planning) in terms of scientific, our country is behind world countries such as India, Pakistan, Malaysia, Singapore, etc. Due to lack of planning and motivation, Iranian scholars have not felt the necessity to tackle this problem so they have limited their role to only aimless teaching. The only objective that can be observed within authorities' general policy making is to develop teaching slightly and as it doesn't follow planning and logic, it uses only a part of our experts (Feridoun, 2004). As long as these static universities stick to repeated humdrum and official teaching following traditional style and creating large masses of graduates, incompetent and ready to work, how on the earth they can play their part in reaching sustainable development (Farasatkhah \& Kebriyaie, 1997). On the other hand, population boost and lack of job opportunities for the youth have increased the demand for higher education and this issue along with some other factors mentioned above have dropped the quality of university system.

Therefore, all countries find it necessary to develop higher education system by means of its nature and mission in order to reach to a competitive edge. Iran's higher education system along with other countries have set new policies on higher education in order to realize the countries' development objectives, especially 20-year perspective plans such as reaching the top power of the region (particularly within scientific realm). However, various studies on the state's higher education show that there is no coherent and organized planning regarding desirable use of higher education courses and their capacities are not sufficiently used. In many cases such as structure, curriculum orientations and objectives, teaching and learning strategies, assessment strategies of student performance, capacity increase, the state of thesis 
guidance, etc., these courses are looked at just like bachelor ones. This issue certainly derails higher education from its initial goals, does not make the country close to knowledge borders as a dynamic scientific community and makes it fail to reach development goals. Thus, it is essential for this trend to be corrected. One of the effective attempts is to pay attention to the quality of higher education courses.

As mentioned earlier, curriculum as a field of expertise is one of the most controversial fields of human knowledge. Because it is about a century since this specialized field was born, there is still less consensus on the dimensions, elements and its components among the due experts. Each of the curriculum scholars expresses various views regarding curriculum elements and steps. Taylor (1949) maintained that curriculum elements include: aims and goals, learning experiences, arrangement and evaluation. Zaies (1976) considered objective, content, learning activities and evaluation methods as curriculum components. For Eisner (1985), curriculum components include objective, content, various learning opportunities, content arrangement, answer and evaluation methods (Gourchiyan \& Tansaz, 1995). Taba (1962) developed Taylor's four elements into seven: needs, objectives, content, content arrangement, learning experiences, arrangement of learning experiences and evaluation. Feresien adopting scientific approach and expanding Tabas' pattern has introduced curriculum components within a framework of 11 steps: problem identification, problem recognition, seeking various solutions, selection of the best solution, affirming the solution, staff's guidance and evaluation of curriculum effectiveness.

For Clain, curriculum contains 9 components: objective, educational materials, content, learning activities, learning strategies, assessment, grouping, time and space/place (Fathi Vajargah \& Shafie, 2007). Saunders (2007) consider curriculum components to be: objective, content, sequence, students, educational processes, educational sources and assessment. Hosseini (2009) quotes Taylor for curriculum components often referred to discussions relevant to curriculum patterns. They are: objective, content, learning and teaching activities and assessment methods.

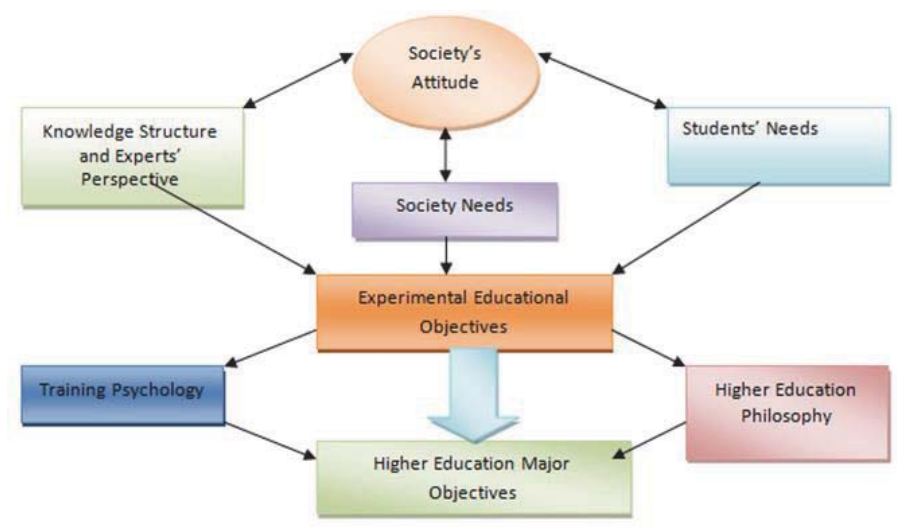

Figure 1. Sources Determining Curriculum Objectives Adopted from Sha'bani (1992, p.160).

Considering the importance of higher education quality in social, economic, cultural and political development of any society, transparency of the affairs and accountability of higher education institutions are necessary. Hence, revision and modification in structure, missions and goals of higher education must be seriously take into consideration as a novel approach in management and planning of higher education officials and authorities so that universities can play an effective role in producing knowledge and taking responsibility for now and future economic and social needs of Iran. Meanwhile, curriculums as the core for higher education systems play a determining and undeniable role in realizing higher education objectives and missions in terms of quality and quantity. To be more specific, curriculums are the true mirrors of progress rate and responsibility which universities take to meet the changing needs of the society (Fathi Vajargah \& Shafie, 2007, 2007). Curriculums as information carrier and cadence of growth, knowledge acquisition and production, enjoy a high significance. Thus, their quality forms the prevailing issue for higher education (Sarmad \& Vaziri, 1998). Also, continuous improvement of quality of education requires analyzing the current situation and identifying strengths and weaknesses. In this respect, using students' opinions as the main beneficiaries of education is helpful (Ahmadzadeh, \& Shokri, 2013), especially those curriculums counted as the basic and vital components of higher education system. They must cover extensive objectives including social, cultural, political, scientific, moral and 
intellectual (Sardabi, 2013).

All the discussions reveal the need for fundamental change in the structure, process and curriculum components within higher education system. Thus, according to the necessities discussed, high importance of the issue in Iran's present community and as the majority of evaluation students rarely, if ever, deal with curriculums systematically and comprehensively and also knowing that these evaluations would not end up in comprehensive, clear information on the curriculum influential components, the necessity for doing this study was justified. The present study attempts to assess the quality of higher education curriculum comprehensively in Bu-Ali Sina universities to meet the needs and expectations of the professors and students and provide the university officials with the results so that it can take steps to modify and improve the curriculums and subsequently increase the quality.

\section{Research Questions Are}

1. To what extent, objectives, content, implementation strategies and curriculum assessment strategies of higher education have met the needs and expectations of the students?

2. To what extent, objectives, content, implementation strategies and curriculum assessment strategies of higher education have met the needs and expectations of the students?

3. Is there a significant difference between demographic features of students and professors with their views on each component of the curriculum?

\section{Method and Materials}

This is an applied study with a descriptive-survey method. The population consists of all higher education students of Human Sciences Department (140 people) and the professors (20) in 2013-2014. The sample volume estimated by Morgan table was 103 students and 16 faculty members. Sampling was carried out using simple random sampling. Data collection tool was a self-made questionnaire including 68 items. Its validity and reliability were estimated by content and formal and Cronbakh's alpha coefficient of 0.94 respectively. To analyze the data taken from the questionnaire, descriptive and inferential statistics (t single sample and independent) was used.

\section{Results}

In this section, we would like to analyze the data. This is done through both descriptive and inferential statistics. It must be noted that descriptive statistics is valuable as affirmed by inferential statistics and it cannot be a strong reason on its own. Both descriptive and inferential statistics are gained by SPSS software. Tables 1 and 2 relate to descriptive and inferential statistics of students' perspective on curriculum objectives, content, implementation strategies and assessment strategies. And tables 3 and 4 relate to professors' view on curriculum objectives, content, implementation strategies and assessment strategies. In some ways, tables 5 and 6 compare students" and professors' views on curriculum objectives, content, implementation strategies and assessment strategies. Then, based on each of the tables, the results will be discussed.

Question 1: to what extent, the objectives, content, implementation and assessment strategies of the higher education curriculum have met the needs and expectations of the students?

Table 1. Descriptive Statistics of Students' Perspective regarding the Curriculum Components: Objectives, Content, Implementation and Assessment Strategies

\begin{tabular}{|lccc|}
\hline Statistical Index & Mean & Standard Deviation & Mean's Standard Error \\
Curriculum Components & $46 / 90$ & 9.47 & 0.92 \\
\hline Curriculum Objective & $45 / 68$ & 10.44 & 1.02 \\
Curriculum Content & $77 / 59$ & 16.21 & 1.58 \\
Curriculum Implementation Strategies & $39 / 80$ & 9.10 & 0.89 \\
Curriculum Assessment Strategies & 39 \\
\hline
\end{tabular}

According to table 1, it is clear that the mean for all components of higher that the population mean, meaning that when a component's mean is higher that the population's, it is safe to conclude that that give component has reasonably met the needs and expectations of the students and vice versa. When a component's mean equals that of the population, it has 
succeeded in meeting the expectations of students and professors to a certain extent. Based on these explanations and table 1, it is predictable that from students' perspective, all curriculum components have reasonably met the students' needs and expectations. In order to gain more exact results, t-tests must be used. We will deal with these tests later.

Table 2. Single Variable t-test of Students' Perspective regarding Curriculum Components: Objectives, Content, Implementation and Assessment Strategies

\begin{tabular}{|lccccc|}
\hline Inferential statistics & \multicolumn{2}{l|}{ Mean of Sample } & Mean of Population Degree of Freedom T value & Sig \\
Curriculum Components & 46.90 & 45 & 103 & 2.04 & 0.04 \\
\hline Curriculum Objective & 45.68 & 45 & 103 & 0.66 & 0.50 \\
Curriculum Content & 77.59 & 75 & 103 & 1.63 & 0.10 \\
Curriculum Implementation Strategies & 39.80 & 39 & 103 & 0.90 & 0.36 \\
Curriculum Assessment Strategies & 39.803 &
\end{tabular}

According to this table, it is obvious that the mean of curriculum components (objectives, content, implementation and assessment strategies) is different from the mean of the population, noting that objective (0.04) is the only significant component. The others are different but not significant ( $p>0.05)$.

Question 2: to what extent, objectives, content, implementation and assessment strategies of higher education curriculum have met the needs and expectations of the professors?

Table 3. Descriptive Table of Professors' Perspective, regarding Objectives, Content, Implementation and Assessment Strategies of the Curriculum

\begin{tabular}{|lccc|}
\hline Statistical Index & Mean & Standard Deviation & Mean's Standard Error \\
Curriculum Components & 53.81 & 4.66 & 1.16 \\
\hline Curriculum Objective & 52.87 & 4.97 & 1.24 \\
Curriculum Content & 93.12 & 8.32 & 2.08 \\
Curriculum Implementation Strategies & 45.50 & 5.30 & 1.32 \\
Curriculum Assessment Strategies & & \\
\hline
\end{tabular}

According to table 3 , it is clear that curriculum components are higher than populations' mean, that is, these components have reasonably met the needs and expectations of the students.

Table 4. Single Variable t-test of Professors' Perspective, regarding the Curriculum's Objective, Content, Implementation and Assessment Strategies

\begin{tabular}{|lccccc|}
\hline $\begin{array}{l}\text { Inferential statistics } \\
\text { Curriculum Components }\end{array}$ & \multicolumn{2}{l}{ Mean of Sample } & Mean of Population & Degree of Freedom T value & Sig \\
\hline Curriculum Objective & 53.83 & 45 & 15 & 7.55 & $0 / 001$ \\
Curriculum Content & 52.87 & 45 & 15 & 6.32 & $0 / 001$ \\
Curriculum Implementation Strategies & 93.12 & 75 & 15 & 8.70 & 0.001 \\
Curriculum Assessment Strategies & 45.50 & 39 & 15 & 4.90 & $0 / 001$ \\
\hline
\end{tabular}

According to this table, one can observe that there is a significant difference between the mean for curriculum components and that of the population in this order: $0.001,0.001,0.001,0.001$ and $p<0.05$. Because the sample's mean is lower than the population's, the professors believe that university curriculum has not met their needs and expectations.

Question 3: is there a significant difference between the perspective of students and professors regarding each of the curriculum components?

Table 5. T-Test of Two Independent Groups, Perspective of Students and Professors Regarding Curriculum Components

\begin{tabular}{|llccccc|}
\hline Variable & Group & $\mathrm{N}$ & Mean & Standard's Deviation & T value & Significance Level \\
\hline Curriculum Objective & Student & 104 & 46.90 & 9.47 & -2.85 & $0 / 005$ \\
& Professor & 16 & 53.81 & 4.66 & & \\
Curriculum Content & Student & 104 & 10.44 & 10.44 & -2.69 & $0 / 008$ \\
\hline
\end{tabular}




\begin{tabular}{|c|c|c|c|c|c|}
\hline Curriculum Implementation Strategies & $\begin{array}{ll}\text { Professor } & 1 \\
\text { Student } & 10 \\
\text { Professor } & 10\end{array}$ & $\begin{array}{lc}6 & 4.97 \\
04 & 16.21 \\
6 & 8.32\end{array}$ & $\begin{array}{c}4.96 \\
16.21 \\
8.32\end{array}$ & -3.74 & 0.001 \\
\hline Curriculum Assessment Strategies & $\begin{array}{ll}\text { Student } & 10 \\
\text { Professor } & 1\end{array}$ & $\begin{array}{ll}04 & 9.10 \\
6 & 5.30\end{array}$ & $\begin{array}{l}9.10 \\
5.30\end{array}$ & -2.43 & 0.01 \\
\hline
\end{tabular}

t-test results show that there is a high difference between t-test and significant level of curriculum components: $t$ value for the component of objective is $t=-2.85$ and significant level of 0.005 ; for the content $t=3.69$ and significant level of 0.008 ; for implementation strategies $t=3.74$ and significant level of 0.001 and for assessment strategies $t=2.43$ and significant level of $0.01(p<0.05)$. Accordingly, one can say that students and professors have different perspectives to curriculum components.

\section{Discussion and Conclusion}

Curriculums as the core of higher education systems play a noticeable and undeniable role in realizing the objectives and missions of higher education in terms of both quality and quantity. Higher education programs play a fundamental role I realizing the state's development objectives, especially those of Iran's 20 year perspective plan through training elites, legislators, lawyers, doctors, engineers, economists, experts, professors, researchers, scientific and political dignitaries, managers and operators of public and national affairs as well as the production of knowledge and technology. Meanwhile, the assessment of inner quality of the curriculum would significantly enhance the curriculum's content and help realize university objectives and missions for training efficient and effective forces.

According to the results, four essential components of the curriculum (objective, content, implementation strategies and assessment strategies) have met the needs and expectations of students and professors. Also, there is a difference between the perspectives of students and professors regarding curriculum components so these two groups' perspective to implementation strategy is different.

\section{Applied Suggestions}

Given the results of the study, the following suggestions are provided to improve the quality of the curriculums:

1. They must have transparency in the field of education; provide knowledge, services, thinking skills (innovative thinking, critical thinking and power of analysis), communication teamwork skills and attitude (having a positive attitude to the world, society, individual and job).

2. Stressing on training job independence, decision-making power, confidence among students, information literacy skills among students (search, analysis, organization, evaluation and proper use of information), lifelong learning, creating enthusiasm and motivation among students for permanent learning, developing the potential to face different and unpredictable (risk taking power) situations among students.

\section{Curriculum Content}

Curriculum content must be consistent with the syllabi, selected content to the working needs and interests of students, changes in the market, educational and research objectives of the curriculum; offer professional services and knowledge diffusion, curriculum entrepreneurship, the growth of attitudes and values among students; considerthe knowledge of a given major with others; increase the depth of knowledge in line with knowledge production,; involve the basic books as the fundamental basis for the majors; have enough flexibility on the syllabi and consider optional books to correspond to students' working fields; create significant experience among students, existence of dynamism, flexibility of syllabi,; move on the latest scientific findings, existence of enough balance between the quality and quantity of the content provided and applicability of the content ( a coordinated combination of theoretical and practical education).

\section{Implementation Strategies Include}

Offering syllabi and clarification of students' duties in the first semester, existence of enough coordination and correspondence between teaching activities and syllabi, using a range of teaching strategies such as presentation, solving problems, group discussion consistent with the type of the lesson, existence of a challenging environment in the process of teaching-learning and students' active contribution within, existence of opportunities for training intellectual 
skills such as discussion, critical thinking, innovative power among students and scientific skills like: brainstorming, simulation and offering novel theories among students, existence of rich learning experiences (learning how to use issues and its correspondence with life realities), creating capacities among students to associate their learning of a book to those of another, training communication and teamwork skills, creating qualitative and quantitative relevance among determined assignments (training and research), giving proper and on time feedback on the level and quality of students' assignments to remove learning deficiencies, existence of mobility, enthusiasm and provoking the need for learning to solve scientific problems and strengthen the spirit of research among students, creating appropriate mechanism to make a bridge between students and professors with research centers and valid universities of home and abroad, supporting professors and students to implement various teaching techniques, considering professors' expertise and ability in relegating theses' guidance.

\section{Curriculum Assessment Strategies have the Potential}

1. to aware students and professors of the purpose and philosophy of evaluation system, existence of a permanent structure in university in order to sustain the curriculum assessment, a mechanism for knowing about employers' needs and expectations to learn the curriculum strengths and weaknesses, a mechanism for knowing about students' needs and expectations to learn the curriculum strengths and weaknesses, the emphasis of assessment strategies of students' performance on recognition and improving students' weaknesses.

2. the emphasis of assessment strategies of students' performance on the intersection of assessment method with curriculum objectives, creating motivation in students and subsequently positive impact on learning; the emphasis of assessment strategies of students' performance on the stability of evaluation methods (grading stability), creating a mechanism to evaluate students' performance accurately and fairly, using a continuous evaluation and not relying on final semester evaluation, considering the limitation and balance between normative evaluation(a comparison among students) and criterion, using various evaluation methods like working set, paper writing, holding seminars and encouraging students to evaluate self-performance.

However, the existing evidence represents the gap between aforementioned items and not using available capacities to improve quality along with quantity in higher education and also there is not enough activities for scientific development of the country.

\section{References}

Abolgasem, B.; Mohammad, S. \& Mohammad Reza, S. (2011) Analyzing Factors Affecting the Improvement of Higher Education Quality from Students' View. Educational management quarterly, 2: 29-50

Ahmadzadeh, A. \& Shokri, A. (2013). Quality Assessment of Tabriz Azad University Educational Services, regarding Students' Perspective drawing on Sir Coal, abstract of proceedings. The first national conference on the quality of higher education. June 2013. Iran.

Eisner, E. W. (1985). The Art of Educational Evaluation. Lewes: Falmer Press.

Farasatkhah, M. \& Kebriyaie, A. (1997). Higher Education in 21st Century (A report on Higher Education Global Conference, 1998). Higher Education Research and Planning Quarterly, 17: 119-129.

Farasatkhah, M. (2006). Status and Mechanism of "Scientific Professional Morals" in Assurance of Iran's Higher Education Quality. Quarterly of Ethics in Science and Technology, 1: 79-93.

Fathi Vajargah, K. \& Shafie, N. (2007). Evaluating University Curriculum Quality (Adults' Education). Quarterly of Curriculum Studies, 2(5): $1-27$.

Feridoun, A. (2004). Higher Education and National Development. in Proceedings of Higher Education and Sustainable Growth. PP. 213-227

Ghassabi Chourasi, M., Shahnazi, A. \& Sanapour, A. (2013a). Analyzing Organizational Culture using Quality Components in Tabriz Azad University. $1^{\text {st }}$ National Conference on the Quality of Higher Education, June, Iran.

Ghassabi Chourasi, M.; Rostami, M. \& Shakourzadeh, R. (2013b) Higher Education and Necessity of Curriculum Quality Assessment. 1st National Conference on the Quality of Higher Education, June, p. 83

Gourchiyan, N. \& Tansaz, F. (1995) A Picture of Curriculum Developments' Trend as a Specialized Major from Ancient Time to Present. Tehran: Higher Education Research and Planning Institution.

Hawasbeigi, F. (2009). Quality Assessment of M.A. Curriculum on Educational Planning from the Perspective of Faculty Members and Students across Tehran State-run Universities. M.A. Dissertation, faculty of psychology and Education. University of Tehran.

Hosseini, M. (2009). Quality Assessment of Isfahan University Higher Education Curriculum. M.A. Dissertation. University of Allameh Tabataba'i. 
Iranmanesh, M. \& Kamerani, E. (2004) Higher Education Role in Sustainable Development. In Proceedings of the Higher Education and Sustainable Development. PP. 33-52

Javedani, H. (1998). World Declaration of Higher Education for the next Century. Tehran: Research and Planning Institute for Higher Education.

Saleholiya, M. (1997) Total Quality Management and its Status in Higher Education. Higher Education Research and Planning Quarterly, 18: $18-32$.

Sardabi, S. (2013) Analyzing Quality of Higher Education Curriculum to Improve Educational System. Proceedings' Abstract. First National Conference on Higher Education Quality. June 2013. Iran.

Sarmad, Z. \& Vaziri, M. (1997). Quality Indexes of Curriculum in Higher Education. Alzahra University Human Sciences Quarterly. 7 , 8(24, 25): 151-165.

Saunders, Sh. T. (2007). Perceptions of quality in cross - border higher education at sojourner-Douglass Bahamas Campus. Morgan state university. ProQuest Information and learning Company, p.221.

Sha'bani, H. (1992). Educational and Training Skills (Teaching Methods and Techniques). Tehran: Samt Press.

Sha'bani, Z. (2006). Designing and Providing a Comprehensive Approach to Merge Curricula in Human Sciences. Higher Education Research and Planning Quarterly. 1(5): 19-47.

Taba, H. (1962). Curriculum Development: Theory and practice, New York: Harcourt Brace and World.

Tyler, R.W. (1949) Basic principles of curriculum and instruction. Chicago: The University of Chicago Press.

Wheelahan, L. \& Carter, R. (2001). National Training packages: A new Curriculum Framework for Vocational education and Training in Australia. Education and Training. 43(6): 303-316.

Zais, S R. (1976). Curriculum: Principles and Foundations. New York: Thomas Y. Crowell Co. 